\title{
Characterization of the full-length human Grb7 protein, and a phosphorylation representative mutant
}

Andrew M. Bradford ${ }^{a}$, Rajan Koirala ${ }^{c}$, Chad K. Park ${ }^{b}$, and Barbara A. Lyons ${ }^{c *}$

${ }^{a}$ Agena Bioscience, 4755 Eastgate Mall, San Diego, CA 92121; ${ }^{b}$ Analytical Biophysics Core, Department of Chemistry and Biochemistry, University of Arizona, Tucson, AZ 85721; ' Department of Chemistry and Biochemistry, New Mexico State University, Las Cruces, NM 88003

Correspondence should be addressed to:

Dr. Barbara A. Lyons

Department of Chemistry and Biochemistry

MSC 3C, P.O. Box 30001

Las Cruces, New Mexico 88003-8001

$575-636-4072$

blyons@nmsu.edu 


\section{Abstract}

It is well known the dimerization state of receptor tyrosine kinases (RTKs), in conjunction with binding partners such as the Grb7 protein, plays an important role in cell signaling regulation. Previously we proposed, downstream of RTKs, that the phosphorylation state of Grb7SH2 domain tyrosine residues could control Grb7 dimerization, and dimerization may be an important regulatory step in Grb7 binding to RTKs. In this manner, additional dimerization-dependent regulation could occur downstream of the membrane-bound kinase in RTK-mediated signaling pathways. Extrapolation to the full-length Grb7 protein, and the ability to test this hypothesis further, has been hampered by the availability of large quantities of pure and stable full-length protein. Here we report the biophysical characterization of the full-length Grb7 protein, and also a mutant representing a tyrosine-phosphorylated Grb7 protein form. Through size exclusion chromatography and analytical ultracentrifugation we show the phosphorylated-tyrosinemimic Y492E-full-length-Grb7 protein (Y492E-FL-Grb7) is essentially monomeric at expected physiological concentrations. It has been shown previously the wild-type fulllength Grb7 (WT-FL-Grb7) protein is dimeric with a dissociation constant $\left(K_{d}\right)$ of approximately 11 uM (Porter et al., 2007). Our studies here measure a full-length protein dimerization $K_{d}$ of WT-FL-Grb7 within one order of magnitude, at approximately $1 \mathrm{uM}$. The approximate size and shape of the WT-F-Grb7 in comparison to the tyrosinephosphorylation mimic Y492E-FL-Grb7 protein was determined by dynamic light scattering methods. In vitro phosphorylation of the Grb7-SH2 domain indicates only one of the available tyrosine residues is phosphorylated, suggesting the same phosphorylation pattern could be relevant in the full-length protein. The biophysical characterization studies in total are interpreted with a view towards understanding the functionally active Grb7 protein conformation. 
Keywords: cancer, cell migration, Grb7 regulation, oligomerization, tyrosine phosphorylation.

\begin{abstract}
Abbreviations: AUC, Analytical Ultracentrifugation; $6 \mathrm{His}$, six histidine residue protein tag used for purification; BPS, between pleckstrin and SH2; DLS, Dynamic Light Scattering; DTT, dithiothreitol; ErbB2, erythroblastosis oncogene B 2; FL, full-length; Grb7, growth factor receptor bound protein 7; GST, glutathione S-transferase protein tag used for purification; MES, 2-(N-morpholino)ethanesulfonic acid; $\mathrm{PH}$, pleckstrin homology; RA, Ras associating; SEC, size exclusion chromatography; SH2, Src homology 2; Ve/Vo, the ratio of the elution volume to the void volume of the column; WT, wild-type.
\end{abstract}




\section{Introduction}

Growth factor receptor-bound protein 7, 10 and 14 (Grb7, Grb10 and Grb14, respectively) comprise a family of Src homology $2(\mathrm{SH} 2)$ domain-containing Grb proteins discovered through CORT (cloning of receptor target) screening (Ooi et al., 1995, Daly et al., 1996). A homologous Caenorhabditis elegans protein, Mig-10, is involved in neuronal migration during development (Manser et al., 1997). The members of this family all contain an N-terminal Pro-rich region, a Ras associating-like domain (Wojcik et al., 1999), a pleckstrin homology domain, a between pleckstrin and SH2 (BPS) domain and a C-terminal SH2 domain (Figure 1A). The Ras associating, pleckstrin homology and BPS domains are also known as the "Grbs and Mig" (GM) domain. Mig-10 does not contain a C-terminal SH2 domain but instead replaces this with a Pro-rich sequence at the C-terminal (Manser et al., 1997).

Many studies have elaborated the link between Grb7 expression and the development of early metastases in cancers (for a review see Han et al., 2001). Besides its accepted roles as a cancer marker (Lacle et al., 2015, Saito et al., 2012) and potential therapeutic target (Pero et al., 2007, Pradip et al., 2013, Spuches et al., 2007, Tanaka et al., 2006, Villalobo et al, 2013) Grb7 has been shown to function in the formation of stress granules (Krisenko et al., 2015, Tsai et al., 2008), in rheumatoid arthritis (Kim et al., 2006, Xiao et al., 2016), and calmodulin signaling (Villalobo et al., 2013).

Members of the Grb7 protein family have been shown to exist in higher oligomeric forms. Grb10 can undergo tetramerization in mammalian cells (Dong et al., 1998). Stein et al. (2003) showed, using gel filtration and sedimentation equilibrium studies, that both the $\mathrm{SH} 2$ domain and the full length Grb10 protein exist in multimeric forms. The Grb7 full-length protein, as well as its RA domain and $\mathrm{SH} 2$ domain alone, is also capable of forming dimers and/or higher multimeric forms (Godamudunage et al., 2017, Ivancic et al., 2005, Porter et al., 2005). Previous work in our laboratory has 
additionally demonstrated the Grb7RAPH domains engage in an intramolecular interaction with the C-terminal SH2 domain (Siamakpour-Reihani et al., 2011). Based upon this observation we hypothesized such an intramolecular association could constitute a form of Grb7 regulation (Figure 1B).

The RAPH domain region is important in protein-protein interactions and can act as a discreet functional unit (Depetris et al., 2009, Paudyal et al., 2013, Qamra \& Hubbard, 2013, Qian et al., 2016, Siamakpour-Reihani et al., 2009, Siamakpour-Reihani et al., 2011). There is evidence this region is also capable of oligomerization. Dong et al. (1998) provided a model for tetramerization of the Grb10 protein. According to that model, oligomerization occurs through the BPS, SH2 and PH domains. Also, the Grb10 and Grb14 RAPH domains may form integrated dimeric structural units of their own (Depetris et al., 2009). While there are structures available for the Grb10 and Grb14 RAPH domains (PDB \#s 3HK0 and 4K81), there is no structure existent of the Grb7 RAPH domains, nor of any of the full-length Grb7 family proteins. Therefore, the folded tertiary conformation, and inter-domain contacts, of the full-length Grb7 protein are unknown.

A mechanism for Grb7 regulation has been suggested (Siamakpour-Reihani et al., 2009, Siamakpour-Reihani et al., 2011) whereby tyrosine phosphorylation of the $\mathrm{RAPH} / \mathrm{SH} 2$ domains relieves the RAPH/SH2 intramolecular interaction. In the model, loss of interaction with the $\mathrm{SH} 2$ domain consequently increases access to the RA and $\mathrm{PH}$ domains for further downstream signaling (Figure 1B). Although this mechanism elucidates a potential functional role for regulation of the Grb7RAPH region, how the oligomerization state of the Grb7 protein is controlled and the importance of this oligomerization for function, is yet to be completely understood. In this study, we report our first efforts to characterize the physical state of the full-length human Grb7 protein, and additionally a phosphorylation-representative mutant of full-length Grb7 (Y492E). 
The selection of the Y492E full-length Grb7 mutant as a phosphorylation representative mutant (in comparison to other potential tyrosine phosphorylation sites) was based upon phosphorylation site prediction software (Supplemental Data Figures S-1 and S-2) as well as in vitro tyrosine phosphorylation results reported herein using c-Src kinase acting upon the Grb7SH2 domain. In addition, efforts to date to generate sufficient quantities of other potential FL-Grb7 phosphorylation representative mutants, such as Y269E, Y260E, or Y284 (see Supplemental Data, Figure S-1), have been unsuccessful. These studies were undertaken in an effort to shed further light on how tyrosine phosphorylation may regulate domain accessibility in the Grb7 protein.

\section{Methods}

\section{Site-Directed Mutagenesis}

The QuikChange II site-directed mutagenesis kit (Agilent, Santa Clara, CA) was used to introduce the Grb7-Y492E, Grb7-Y492F, and Grb7-F511R mutations into the pET303-Grb7 and pET302-Grb7 plasmid constructs following the standard protocol as provided by Agilent. Oligonucleotide primers (Supplemental Data Figure S-3) were designed using Agilent's online primer design tool, (http://www.genomics.agilent.com/primerDesignProgram.jsp), and ordered from IDT (Coralville, IA). The Grb7-SH2 domain mutations were generated as described previously (Peterson et al., 2012). Briefly, a pGEX2T-Grb7-SH2 construct (Brescia et al., 2002) was used as template in the QuikChange II site-directed mutagenesis protocol to produce plasmid constructs encoding the mutants Y68F-Grb7SH2, Y80E-Grb7SH2, Y80F-Grb7SH2, Y68F/Y80F-Grb7SH2, and F99R-Grb7SH2.

\section{Protein Expression and Purification}

Plasmid Vector Construction 
The coding sequence for full-length human Grb7 variant 1 was subcloned into pET303 by PCR amplification using pCMV-Myc-Grb7 as the template (SiamakpourReihani et al., 2009). PCR product was performed using Phusion High-Fidelity DNA Polymerase (New England BioLabs, Inc. (NEB), Ipswich, MA) and oligonucleotide primers 5'-GAG ATC TAG AAT GGA GCT GGA TCT GTC TCC ACC TCA TCT T-3' (forward) and 5'-GAG ACT CGA GGA GGG CCA CCC GCG TGC-3' (reverse). The PCR product was directionally cloned between Xbal and Xhol restriction sites of pET303 using standard molecular biology techniques. DNA sequencing using T7 and T7 terminator primers followed by BLASTx analysis verified that the insert was $100 \%$ identical to full-length Grb7 variant 1 (gi|334883156|ref|NM_005310.3|). This plasmid construct allows overexpression of full-length Grb7 in E. coli and facilitates its purification due to the presence of a C-terminal hexa-histidine tag. Indeed, after expression and purification, a protein band appeared at around $60 \mathrm{kDa}$ by SDS-PAGE, which was detectable by Western blot using Grb7 antibodies (H70 and C20) to the N-terminus and C-terminus, respectively (not shown). In addition, an N-terminal hexa-histidine tagged full-length Grb7 construct, with a thrombin cleavage site between hexa-histidine tag and Grb7, was similarly constructed and verified, using oligonucleotides 5'-GAG AGA ATT CCC 61 TGG TTC CGC GTG GAT CCA TGG AGC TGG ATC TGT CTC CAC C-3’ (forward) and 5'-GAG AGA ATT CTC ATC AGA GGG CCA CCC GCG TGC-3' (reverse), for insertion into the EcoRI site of pET302. Grb7-RAPH and Grb7-SH2 constructs have been previously described (Siamakpour-Reihani et al., 2009, Brescia et al., 2002).

\section{Protein Expression}

Plasmid constructs were transformed into Rosetta competent cells (Millipore, Billerica, MA), which are well suited for eukaryotic protein expression. One-liter cultures were grown in LB using the appropriate selective antibiotics: chloramphenicol $(34 \mu \mathrm{g} / \mathrm{mL})$ 
for the pRARE plasmid in the Rosetta strain, and ampicillin $(100 \mu \mathrm{g} / \mathrm{mL})$ for the $\mathrm{pET}$ vectors. Cultures were grown at $37^{\circ} \mathrm{C}$ with $225 \mathrm{rpm}$ shaking until $0.55 \mathrm{OD} 600$, and then protein expression was induced with $1 \mathrm{mM}$ IPTG. Expression occurred overnight at $17^{\circ}$ C with shaking at $200 \mathrm{rpm}$. Cells were harvested by centrifugation at $5500 \mathrm{xg}$ for 15 minutes at $4{ }^{\circ} \mathrm{C}$ and the pellets stored at $-20^{\circ} \mathrm{C}$ until further use.

\section{Protein Purification}

Purification of hexa-histidine-tagged proteins (WT-FL-Grb7 and Y492E-FL-Grb7) was performed by batch method using Ni-NTA agarose (Qiagen, Valencia, CA). A 1 L culture pellet was re-suspended in $30 \mathrm{~mL}$ of lysis buffer $\left(50 \mathrm{mM} \mathrm{NaH} \mathrm{PO}_{4}, 300 \mathrm{mM}\right.$ $\mathrm{NaCl}, 10 \mathrm{mM}$ imidazole, $10 \mathrm{mM} \beta$-mercaptoethanol (BME), $0.5 \mu \mathrm{g} / \mathrm{mL}$ pepstatin, 0.5 $\mu \mathrm{g} / \mathrm{mL}$ leupeptin, $50 \mu \mathrm{M}$ phenylmethylsulfonyl fluoride (PMSF), $\mathrm{pH} 8.0$ ), and then sonicated on ice 5 times for 12 seconds (pulsed for $0.6 \mathrm{~s}$ on/ $0.4 \mathrm{~s}$ off) at $60 \%$ amplitude, with one minute between each sonication. To the sonicated cells, $900 \mu \mathrm{L}$ Triton X-100 was added, and the mixture was rocked for 30 minutes at room temperature. After centrifugation at $15,000 \times \mathrm{g}$ for 10 minutes, the clarified lysate was added to $3 \mathrm{~mL}$ Ni-NTA agarose and rocked at $4{ }^{\circ} \mathrm{C}$ for $1 \mathrm{~h}$ to overnight. The lysate/NiNTA resin was poured into a gravity column. The settled Ni-NTA agarose beads were washed with $30 \mathrm{~mL}$ wash buffer $\left(50 \mathrm{mM} \mathrm{NaH}_{2} \mathrm{PO}_{4}, 300 \mathrm{mM} \mathrm{NaCl}, 20 \mathrm{mM}\right.$ imidazole, 10 $\mathrm{mM}$ BME, $\mathrm{pH}$ 8.0). Proteins were eluted from the Ni-NTA agarose with $12 \mathrm{~mL}$ elution buffer (50 mM NaH${ }_{2} \mathrm{PO}_{4}, 300 \mathrm{mM} \mathrm{NaCl}, 250$ mM imidazole, $10 \mathrm{mM} \mathrm{BME,} \mathrm{pH} \mathrm{8.0).} \mathrm{For}$ full-length Grb7 protein and mutants, the eluted protein from the Ni-NTA agarose was immediately dialyzed into $6 \mathrm{mM} \mathrm{NaH}_{2} \mathrm{PO}_{4}, 85 \mathrm{mM} \mathrm{Na}_{2} \mathrm{HPO}_{4}, 50 \mathrm{mM}$ Imidazole, $200 \mathrm{mM}$ $\mathrm{NaCl}, 2 \mathrm{mM}$ dithiothreitol (DTT), $\mathrm{pH}$ 7.8, overnight. The protein was then prepared for cation exchange by dialyzing into $20 \mathrm{mM}$ HEPES, $100 \mathrm{mM} \mathrm{NaCl}, 5 \%$ glycerol, $1 \mathrm{mM}$ DTT, pH 7.5, then into 20 mM HEPES, 25 mM NaCl, 5 \% glycerol, 1 mM DTT, pH 7.5 
and immediately submitted for purification by cation exchange. The protein solution was filtered $(0.45 \mu \mathrm{m})$, diluted 2-fold with Buffer A (20 mM HEPES, $5 \%$ glycerol, $1 \mathrm{mM}$ DTT, pH 7.5) and loaded onto a HiPrep SP XL 16/10 cation exchange column using an AKTA FPLC system with $A_{280}$ detection. The column was washed with 1.5 column volumes of Buffer $A$, and protein was eluted with a $0 \%$ to $60 \%$ gradient with Buffer B $(20 \mathrm{mM}$ HEPES, $1 \mathrm{M} \mathrm{NaCl}, 5 \%$ glycerol, 1 mM DTT, pH 7.5) over 10 column volumes. A broad peak was observed at approximately $25 \%$ Buffer B. Fractions were collected and analyzed by SDS-PAGE, which showed the Grb7 protein (approximately $60 \mathrm{kDa}$ ) to be essentially pure. Grb7 protein fractions were pooled and dialyzed into 50 mM MES, 100 mM NaCl, 1 mM DTT, pH 6.6 and concentrated using a 10,000 MWCO centrifugal concentrator (Millipore, Billerica, MA). These steps were performed at $4{ }^{\circ} \mathrm{C}$ or on ice, where appropriate.

Purification of the Grb7SH2 domain has been described elsewhere (Brescia et al., 2002), where the Grb7SH2 domain is first expressed as a GST-GRB7SH2 construct that is subsequently cleaved with thrombin to yield the free Grb7SH2 domain. Briefly, a bacterial pellet from a 1-liter culture was re-suspended in $30 \mathrm{~mL}$ lysis buffer (PBS, 0.5 $\mu \mathrm{g} / \mathrm{mL}$ pepstatin, $0.5 \mu \mathrm{g} / \mathrm{mL}$ leupeptin, $50 \mu \mathrm{M}$ phenylmethylsulfonyl fluoride (PMSF), 1 mM DTT, $\mathrm{pH} 7.4$ ) on ice. The solution was sonicated on ice 5 times for 12 seconds (pulsed for $0.6 \mathrm{~s}$ on/ $0.4 \mathrm{~s}$ off) at $60 \%$ amplitude. To the sonicated cells, $900 \mu \mathrm{L}$ Triton X100 was added, and the mixture was rocked for 30 minutes at room temperature. After centrifugation at $15,000 \times \mathrm{g}$ for 10 minutes, the clarified lysate was added to $2 \mathrm{~mL}$ Glutathione Sepharose 4B (GE Healthcare Life Sciences, Piscataway, NJ) and rocked at $4{ }^{\circ} \mathrm{C}$ for $2 \mathrm{~h}$. The beads were washed twice in PBS, $1 \mathrm{mM} \mathrm{DTT}, \mathrm{pH} 7.4$, and then once with PBS, $\mathrm{pH}$ 7.4. Twenty-five units $(5 \mathrm{U} / \mathrm{mL})$ of bovine thrombin were added for on-bead cleavage of Grb7-SH2 from Glutathione Sepharose/GST, with stirring overnight (12-16 h) at room temperature. The suspension was filtered $(0.45 \mu \mathrm{m})$ and incubated with 300 
$\mu \mathrm{L}$ p-aminobenzamidine agarose for 30 minutes at $4{ }^{\circ} \mathrm{C}$ with rocking to remove thrombin. For some of the in vitro phosphorylation reactions, the Grb7-SH2 domain and mutants were further purified by size exclusion chromatography, to remove GST and higher molecular weight contaminants. Grb7-SH2 was dialyzed into 50 mM MES, 100 mM NaCl, 1 mM DTT, pH 6.6, concentrated, and loaded onto a HiPrep 16/60 Sephacryl S-200 HR gel filtration column (GE Healthcare Life Sciences, Piscataway, NJ). The Grb7-SH2 domain and mutants were stored at $4{ }^{\circ} \mathrm{C}$ until used in experiments (usually within one week).

\section{Determination of Protein Concentration}

Protein concentration was determined by UV spectroscopy at $280 \mathrm{~nm}$ using the NanoDrop 2000 (NanoDrop, Wilmington, DE). Theoretical extinction coefficients and molecular weights for each protein were determined using ProtParam (Swiss Institute of Bioinformatics, http://web.expasy.org/protparam/), and used as input for the NanoDrop software to return protein concentration in $\mathrm{mg} / \mathrm{mL}$.

\section{Bacterial Expression and Purification of c-Src Kinase}

c-Src kinase domain used for in vitro phosphorylation reactions was expressed following Seeliger et al. (2005). Briefly, the plasmid pET28a encoding the chicken c-Src kinase domain (a gift from John Kuriyan, University of California, Berkeley), and pCDFDuet-1 containing full-length YopH phosphatase from Yersinia were used to cotransform Rosetta competent cells. Cultures were selected with $50 \mu \mathrm{g} / \mathrm{mL}$ kanamycin, 50 $\mu \mathrm{g} / \mathrm{mL}$ streptomycin and $34 \mu \mathrm{g} / \mathrm{mL}$ chloramphenicol. Cultures were grown to 1.2 OD600 and protein expression was induced with $0.2 \mathrm{mM} \mathrm{IPTG}$. Overnight expression at $17^{\circ} \mathrm{C}$ with shaking at $200 \mathrm{rpm}$ was followed by centrifugation at $5500 \times \mathrm{g}$ for 15 minutes to pellet the cells. Cell pellets were stored at $-20^{\circ} \mathrm{C}$. 
c-Src kinase was purified following Seeliger et al., (2005). Briefly, hexahistidine tagged c-Src kinase was purified by affinity chromatography using Ni-NTA agarose (see section on Grb7 protein purification above for the procedure), anion exchange using DEAE Sepharose Fast Flow resin (GE Healthcare Life Sciences, Piscataway, NJ) followed by size exclusion chromatography using the HiPrep 16/60 Sephacryl S-200 HR gel filtration column (GE Healthcare Life Sciences, Piscataway, NJ). Buffers used are those indicated in the reference. Purified c-Src kinase domain was flash frozen in liquid nitrogen and stored at $-80^{\circ} \mathrm{C}$ until needed.

\section{Circular Dichroism}

CD spectra of wild type and mutant FL-Grb7 proteins were recorded at $4{ }^{\circ} \mathrm{C}$ on a Jasco (Nantes, France) J-810 Spectropolarimeter using a $0.5 \mathrm{~mm}$ quartz cuvette. Proteins were at 0.7 to $0.8 \mathrm{mg} / \mathrm{mL}$ in $50 \mathrm{mM}$ MES, $100 \mathrm{mM} \mathrm{NaCl}, 1 \mathrm{mM}$ DTT, $\mathrm{pH}$ 6.6. Spectra were recorded from 200 to $260 \mathrm{~nm}$ at $1 \mathrm{~nm}$ bandwidth, $4 \mathrm{~s}$ response, 0.1 $\mathrm{nm}$ data pitch and $5 \mathrm{~nm} / \mathrm{min}$ scanning speed. A background spectrum of the buffer was subtracted from all protein CD spectra. Representative CD signal traces can be seen in the Supplemental Data, Figure S-4.

\section{Size Exclusion Chromatography}

Size exclusion chromatography was performed at $4{ }^{\circ} \mathrm{C}$ using an ÄKTA FPLC (Fast Protein Liquid Chromatography) system with a calibrated HiPrep 16/60 Sephacryl S-200 HR gel filtration column (GE Healthcare Life Sciences, Piscataway, NJ). The void volume of the column was determined to be $35 \mathrm{~mL}$ with Blue Dextran 2000, and the column was calibrated using the Gel Filtration Low Molecular Weight Calibration Kit (GE Healthcare Life Sciences, Piscataway, NJ). Specifically, a $500 \mu \mathrm{L}$ mixture of Conalbumin (MW 75 kDa), Carbonic Anhydrase (MW 29 kDa) and Ribonuclease A (MW 13.7 kDa) 
was run through the column and the elution volumes were obtained. A plot of the elution volume divided by the void volume on the $\mathrm{x}$-axis versus the $\log 10 \mathrm{MW}$ on the $\mathrm{y}$-axis for each protein described a linear relationship with an $R^{2}$ value of 0.99928 . The resulting fitted equation was used to calculate the molecular weight of experimental proteins based on their elution volume (Figure 2). Full-length Grb7 proteins and Grb7-SH2 domain proteins were dialyzed into 50 mM MES, 100 mM NaCl, 1 mM DTT, pH 6.6, concentrated to approximately $2-4 \mathrm{mg} / \mathrm{mL}$, and $0.5 \mathrm{~mL}$ samples were injected into the column via a $2 \mathrm{~mL}$ sample loop. The gel filtration column was equilibrated in the same buffer used for dialysis.

\section{Analytical Ultracentrifugation}

Sedimentation velocity (results not shown) and sedimentation equilibrium experiments (Supplemental data section, Figure S-5) were run in a Beckman XL-1 analytical ultracentrifuge. The data were analyzed with SEDFIT (https://sedfitsedphat.nibib.nih.gov/software/), allowing for a continuous sedimentation constant c(s) distribution (Schuck et al., 2002). The partial specific volume and the buffer density and viscosity were calculated using SEDNTERP (Lebowitz et al., 1998, Harding et al., 1992). For velocity experiments, sample protein and buffer solution were loaded into the appropriate sides of a two-sector shaped cell. After allowing thermal equilibration for over $1 \mathrm{hr}$ at $4{ }^{\circ} \mathrm{C}$, the sample was spun at 40,000 rpm $(132,000 \mathrm{~g})$. Absorbance scans were taken continuously for $17 \mathrm{~h}$.

Sedimentation equilibrium experiments on full-length Grb7 proteins were performed at 1, 5, and $9 \mu \mathrm{M}$ concentrations, and at $6500 \mathrm{rpm}(3500 \mathrm{~g}), 9500 \mathrm{rpm}$ (7450 $\mathrm{g})$, and $12000 \mathrm{rpm}(11,890 \mathrm{~g})$, at $4^{\circ} \mathrm{C}$. Equilibrium was established by unchanging RMSD between successive scans that were 4 hours apart. Data were fit to a single species as well as monomer-dimer models for comparison, and treated as a combined multispeed 
experiment in which all three speeds for a single concentration were treated as a single experiment.

\section{Dynamic Light Scattering Measurements}

Protein molecular hydrodynamic diameters were measured by dynamic light scattering (DLS) using a Zetasizer Nano-S (Malvern Instruments, Worcestershire, UK) instrument. Twelve representative measurements were taken for the WT-FL-Grb7 protein, while fifteen were acquired for the Y492E-FL-Grb7 protein. The average hydrodynamic diameter for each protein was calculated from the total measurements for each. Protein concentrations for both the Y492E-FL-Grb7 and WT-FL-Grb7 proteins were $2.5 \mathrm{mg} / \mathrm{mL}(41.3 \mu \mathrm{M})$ and all measurements were acquired at $25{ }^{\circ} \mathrm{C}$.

Dynamic light scattering data allows the determination of the shape of a protein using the Perrin factor and axial ratios. The radius of a hypothetical sphere of homogeneous mass $\left(R_{\text {sph }}\right)$ can be calculated using the following equation where $M_{W}$ is the molecular weight, $\tilde{V}$ is the partial specific volume, and $N_{A}$ is Avogadro's number (http://www.nanosafe.org/home/liblocal/docs/Nanosafe\%202010/2010_oral\%20presenta tions/O7-5_Malvern.pdf).

$$
R_{s p h}=\left(\frac{3 M_{W} \bar{V}}{4 \pi N_{A}}\right)^{1 / 3}
$$

The frictional coefficient of the sphere $\left(f_{M}\right)$ can then be calculated using the equation below, where $\eta$ is the viscosity.

$$
f_{M}=6 \pi \eta R_{s p h}
$$

The same equation can be modified for a non-spherical system by using the hydrodynamic radius $\left(R_{H}\right)$ instead of the $R_{\text {sph }}$. 


$$
f_{H}=6 \pi \eta\left(R_{H}-\text { Solvent layer }\right)
$$

The ratio of the measured frictional coefficient to the frictional coefficient for a hypothetical sphere of the same radius is defined as the Perrin factor $(F) ; F=f_{H} / f_{M}$.

\section{In Vitro Tyrosine Phosphorylation of Grb7-SH2 Domains}

In vitro tyrosine phosphorylation of the Grb7-SH2, Grb7-RAPH, full-length Grb7 and mutants was carried out in $50 \mu \mathrm{L}$ reactions (70 mM MOPS, $\mathrm{pH} 7.2,2.5 \mathrm{mM}$ ATP, 20 $\mathrm{mM} \mathrm{MnCl} 2,15 \mathrm{mM} \mathrm{MgCl}_{2}, 1.2 \mathrm{mM}$ EDTA, $3 \mathrm{mM} \mathrm{EGTA}, 1 \mathrm{mM}$ DTT) at $30^{\circ} \mathrm{C}$ for 2 hours using approximately $1-2 \mu \mathrm{g}$ substrate protein and $100 \mathrm{ng}$ c-Src kinase domain. Detection of phosphotyrosine was by Western blot analysis using mouse monoclonal phosphotyrosine antibody pY20 (Santa Cruz Biotechnology, Dallas, TX). SDS-PAGE of samples was on $12 \%$ Bis-Tris gels with MOPS running buffer, run at $100 \mathrm{~V}$ for 90 minutes. Transfer of proteins to polyvinylidine difluoride (PVDF) membrane was by the semi-dry method at $12 \mathrm{~V}$ for 35 minutes. The transfer buffer used was Bjerrum SchaferNielsen plus $2.0 \mathrm{~g} / \mathrm{L}$ Tris base. Membranes were blocked in $2.5 \%$ BSA/TBST for $2 \mathrm{~h}$ at room temperature. Primary antibody (pY20) was diluted 1:667 in blocking buffer, and the membrane was incubated overnight at $4{ }^{\circ} \mathrm{C}$ with gentle rocking. The membrane was washed 3 times for 10 minutes each with TBST, prior to $1 \mathrm{~h}$ room-temperature incubation with goat anti-mouse/HRP secondary antibody (Thermo Fisher, Hudson, NH) at 1:105 dilution. Membranes were washed 3 times, 10 minutes each with TBST, and then incubated for 5 minutes with SuperSignal West Femto chemiluminescent substrate (Thermo Fisher, Hudson, NH). Chemiluminescence was detected using a Bio-Rad XRS imager at 15-60 s exposure.

\section{Results}




\section{Circular dichroism indicates both the WT-FL-Grb7 and Y492E-FL-Grb7}

proteins are folded

CD spectra were recorded for the WT-FL-Grb7, and Y492E-FL-Grb7 proteins (Supplementary Data, Figure S-2). Appreciable signal is observed at approximately 210, 215 , and $220 \mathrm{~nm}$. These are typical ellipticity regions indicative of the presence of protein secondary structure (Greenfield and Fasman, 1969). There is noticeable noise in the signal below $210 \mathrm{~nm}$, especially for the WT-FL-Grb7 protein. This is likely an artifact of the MES buffer system. The spectra are similar, and indicate both Grb7 proteins are folded and consist of a mixture of $\alpha$-helical and $\beta$-sheet secondary structure.

\section{The full-length Y492E-Grb7 protein is primarily monomeric}

\section{Size Exclusion Chromatography of WT-FL-Grb7 and Y492E-FL-Grb7 proteins}

Size exclusion chromatography of full-length forms of Grb7 and mutants (Figure 2) suggest the phosphotyrosine mimic Y492E-FL-Grb7 protein may be monomeric. Compared to calibration curve standards, the WT-FL-Grb7 protein elutes close to the dimer molecular weight at approximately $110 \mathrm{kDa}$, while both mutants Y492E-FL-Grb7 and F511R-FL-Grb7 elute close to $80 \mathrm{kDa}$, somewhat larger than expected for monomers. These results resemble our previous study on the Grb7SH2 domains alone (Peterson et al., 2012), where the Y80E-Grb7SH2 (equivalent to Y492E in the full-length protein) phosphorylation mimic eluted intermediate of monomer and dimer. In that study, the F99R-Grb7SH2 mutant (equivalent to F511R in the full-length Grb7 protein) eluted at the expected molecular weight of a monomer. The F99RGrb7SH2 is an established monomerizing mutation (Porter et al., 2005).

Full-length Grb7 is a much larger protein and may exhibit differing dynamics in gel filtration studies. Larger proteins sometimes exhibit re-equilibration rates on the time scale of the separation in gel filtration, so what is observed from this technique is usually 
an ensemble of monomer and dimer. In fact, inspection of the gel filtration plot shows somewhat unusually broad peaks, a potential indication of such a phenomenon. If we consider the molecular weight range of the peaks, WT-FL-Grb7 spans from slightly greater than $120 \mathrm{kDa}(1.2 \mathrm{Ve} / \mathrm{Vo})$ to about $55 \mathrm{kDa}(1.55 \mathrm{Ve} / \mathrm{Vo})$. The peak is asymmetrical, with a leading edge toward the higher molecular weight species. This is itself an observation of equilibrium. Both the Y492E-FL-Grb7 and F511R-FL-Grb7 mutant proteins span the range from $110 \mathrm{kDa}$ to $55 \mathrm{kDa}$. In order to more accurately gauge the oligomeric state of these proteins, we turned to analytical ultracentrifugation techniques.

Analytical Ultracentrifugation of the WT-FL-Grb7 and Y492E-FL-Grb7 proteins Sedimentation equilibrium experiments conducted on WT-FL-Grb7 (Supplemental data Figure S-5A) show a single species of $120 \mathrm{kDa}$ and estimate the equilibrium dissociation constant to be near $1 \mu \mathrm{M}$. We tested concentrations of $1 \mu \mathrm{M}, 5$ $\mu \mathrm{M}$ and $9 \mu \mathrm{M}$ each at rotor speeds of $6500 \mathrm{rpm}, 9000 \mathrm{rpm}$ and $12000 \mathrm{rpm}$. We did not observe any monomer at any of the concentrations tested (based upon a monomerdimer equilibrium fit to the data), implying the $K_{d}$ lies below the lowest concentration tested. Deviations from the modelfit were evident in the lowest concentration tested, therefore a conservative estimate of the $K_{d}$ would be at a few micromolar.

Our observed $K_{d}$ is lower than that reported in the literature, where a value of 11 $\mu \mathrm{M}$ was reported (Porter et al., 2007). The concentration of protein used for sedimentation equilibrium experiments in that study was $12 \mu \mathrm{M}$, and it is possible the $K_{d}$ could be lower than the concentration tested. We concluded that our wild type protein behaves in reasonable accordance with the literature value.

Sedimentation equilibrium of the Y492E-FL-Grb7 and F511R-FL-Grb7 proteins (Supplemental data Figure S-5B) showed an increase of the dimerization constant to 
about $17 \mu \mathrm{M}$, approximately 1.5 -fold greater than the reported literature value for the WT-FL-Grb7 protein (Porter et al., 2007), and 17-fold greater than our lowest estimated $K_{d}$ value for the WT-FL-Grb7 protein. For sedimentation equilibrium measurements of the isolated Grb7SH2 domain, one of these mutations, F99R, (equivalent to F511R) afforded an estimated $K_{d}$ between $300 \mu \mathrm{M}$ to $590 \mu \mathrm{M}$ (Peterson et al., 2012).

It is noted this $K_{d}(17 \mu \mathrm{M}$ for the Y492E-FL-Grb7 protein) of dimerization lies above the physiological relevant range of protein-protein interactions, which empirically are typically measured between 1 and $10 \mu \mathrm{M}$. Therefore, at physiologically relevant concentrations, we would expect the major species is monomeric, at approximately $90 \%$ monomer. Similar results are seen for the F511R-FL-Grb7 mutant (Supplemental data Figure S-5C). The F511R mutation is expected to drive the Grb7 protein towards the monomer form, as it is believed to disrupt the $\mathrm{SH} 2$ domain dimerization interface (Porter et al., 2005). These sedimentation equilibrium studies suggest this mutant is also approximately $90 \%$ monomer.

\section{Full-length Y492E Grb7 protein may exist in a partially open conformation}

Dynamic light scattering experiments were performed using the WT-FL-Grb7 and Y492E-FL-Grb7 proteins (Table 1-2, and Figure 3). The average diameter of the WT-FLGrb7 protein was determined to be $9.47 \mathrm{~nm}$. The average diameter of the Y492E-FLGrb7 protein was determined to be $8.03 \mathrm{~nm}$. Both of the FL-Grb7 proteins show additional species of varying diameter (often one other contributing peak of higher diameter), however, according to the size distribution by volume, their presence contributes little to the overall species (Figure 3, panels B and D).

As shown in Table 1, based upon the assumption the protein is globular and approximately spherical in shape, the estimated molecular weight for the WT-FL-Grb7

protein is $128 \mathrm{kDa}$, which is very close to the molecular weight for a Grb7 protein dimer 
(monomer approximately $60 \mathrm{kDa}$ ). The dynamic light scattering (DLS) studies were performed at a concentration of $41.3 \mu \mathrm{M}$ for both the WT-FL-Grb7 and Y492E-FL-Grb7 proteins. Based upon the estimated $K_{d}$ of $1 \mu \mathrm{M}$ for the WT-FL-Grb7, virtually all of the wild type protein would exist as a dimer at this concentration.

The estimated molecular weight for the Y492E-FL-Grb7 protein is $87 \mathrm{kDa}$, suggesting not a dimer but possibly a monomer of aberrant molecular weight. This result is also in concurrence with the size exclusion results reported above, where the Y492EFL-Grb7 protein elutes at a volume consistent with a protein of molecular weight $80 \mathrm{kDa}$, i.e. between the monomer at $60 \mathrm{kDa}$, and the dimer at $120 \mathrm{kDa}$. Because both dynamic light scattering and size exclusion chromatography data results are proportionally related to protein hydrodynamic radius, the result again suggests a Grb7 protein form that is monomeric, but in a conformationally more open structure. It is noted however, that there may be a monomer-dimer equilibrium present for the Y492E-FL-Grb7 protein at the concentration of the DLS studies $(41.3 \mu \mathrm{M})$. The estimated $K_{d}$ based upon the analytical ultracentrifugation studies is $17 \mu \mathrm{M}$, therefore both monomer and dimer forms of the protein may be present and hamper a simple interpretation of the data.

Table 2 shows the estimated values for the Perrin factor (the shape factor) of each construct. Both the WT-FL-Grb7 and Y492E-FL-Grb7 proteins have a Perrin factor of around 1.3. In our hands, this is a common result for proteins that are globular, or approximately spherical in shape. Thus, although dynamic light scattering and size exclusion chromatography studies indicate an apparent molecular weight that could imply a more open conformation, the Perrin factor of Y492E-FL-Grb7 indicates the protein retains an overall globular form. 


\section{The isolated Grb7SH2 domain is phosphorylated in vitro at only one}

\section{tyrosine}

An in vitro tyrosine phosphorylation assay was performed with different Grb7-SH2 domains (wild-type and mutants) and ATP as substrates, using chicken cSrc kinase for enzyme. There are two tyrosines in the Grb7-SH2 domain, tyrosine 68 (Y480 in the full-length protein) and tyrosine 80 (Y492 in the full-length protein), both of which are phosphorylation competent substrates in Tsai et al. (2007) using focal adhesion kinase (FAK). In our hands, however, we were unable to observe any tyrosine phosphorylation of the wild-type Grb7SH2 domain using FAK kinase domain (SigmaAldrich, St. Louis, MO) in vitro, while c-Src kinase phosphorylated it readily (Figure 4A).

Using pY20 antibody, which specifically detects phosphotyrosines, Western blots show a signal for wild-type Grb7SH2 and the mutant F99R-Grb7SH2 protein bands after the in vitro kinase reaction, but no signal for the Y80E-Grb7SH2mutant (Figure 4A). From this we inferred that c-Src kinase does not phosphorylate tyrosine 68.

We next performed in vitro phosphorylation reactions using a comprehensive set of Grb7SH2 domain mutants (Figure 4B), demonstrating that phosphorylation occurs on tyrosine 80 , not tyrosine 68 . This experiment confirmed the previous results, that wild-type Grb7SH2 and the F99R-Grb7SH2 mutant are phosphorylated, while Y80E-Grb7SH2 is not. Additionally, the Y68F-Grb7SH2 mutant was phosphorylated, while the Y80F-Grb7SH2 mutant was not. The tyrosine to phenylalanine mutation is a conservative one, which does not affect the structure or oligomeric status of the domain, at least by circular dichroism and size exclusion analysis (data not shown). This experiment served to eliminate one tyrosine as a substrate in order to observe the phosphorylation state of the other tyrosine after in vitro phosphorylation reactions. 
It is clear under these reaction conditions tyrosine 68 is not a substrate for cSrc kinase, while tyrosine 80 is a substrate. Additionally, the Y68F/Y80F-Grb7SH2 double mutant serves as a negative control, since as expected no phosphotyrosine signal is observed.

\section{Discussion}

The wild type Grb7-SH2 domain and the full-length Grb7 protein are reported to exist primarily in dimeric form (Ivancic et al.,2003, Porter et al., 2005, Porter et al., 2005). Through our studies herein, we sought to determine the oligomeric state of a fulllength Grb7 phosphorylation mimic (Y492E) in order to better understand the role of dimerization in the regulation of the Grb7 protein. We have shown the Y492E-FL-Grb7 phosphorylation mutant to be monomeric by size exclusion chromatography, analytical ultracentrifugation techniques, and dynamic light scattering.

Based upon our analytical ultracentrifugation results, we can conclude mimicking tyrosine phosphorylation of the $\mathrm{SH} 2$ domain in the Grb7 protein increases the equilibrium dissociation constant slightly above the range of physiological relevance, at approximately $17 \mu \mathrm{M}$. Porter et al. (2007) is the only other study to examine full-length Grb7 (to our knowledge), in which sedimentation equilibrium data was obtained. In our work we also performed sedimentation equilibrium, however, we used a range of concentrations and rotor speeds, and consequently our results should be more comprehensive.

Tyrosine 492 in the Grb7 protein is predicted to be a phosphorylation site by the NetPhos 2.0 (Blom et al.,1999) and iGPS servers (Song et al., 2012) (Supplemental Data Figures S-1 and S-2). In addition, we demonstrated in vitro phosphorylation of the $\mathrm{SH} 2$ domain by c-Src is exclusive to tyrosine 80 (corresponding to Y492 in the FL-Grb7 protein). Several groups have shown phosphorylation of Y492 is important to Grb7 
function, ranging from RNA-binding (Tsai et al., 2008) to effects on cell migration (Chu et al., 2009).

Our arguments here do not preclude the possibility the other tyrosine of the Grb7SH2 domain, Y68 (Y480 in the full-length protein) may be phosphorylated within Grb7. It is possible a different kinase may phosphorylate it, although few kinases were predicted to phosphorylate Y68 by the iGPS 1.0 server (none were predicted above the default iGPS cutoff score 1.86, Supplemental Data Figure S-2). Additionally, the NetPhos 2.0 server predicted against tyrosine phosphorylation of Y68 (Supplemental Data Figure S-1). In our laboratory, we were unable to phosphorylate Y68 even with the obviously promiscuous kinase, chicken c-Src kinase. We have previously attempted to purify the Y68E-Grb7SH2 phosphomimic and have not succeeded (data not shown). We suspect the reason to be this mutation causes the protein to be insoluble or otherwise unstable. Inspection of the structure at this mutation site shows a region that is dense with hydrophobic interactions.

Nonetheless, Tsai et al. (2007) report phosphorylation of both Y68 and Y80 by FAK and its effects on mRNA binding. We were unable to observe phosphorylation by FAK in our hands, but it is possible reaction conditions were not optimal or the enzyme was non-functional. Also, we used purified enzyme and Tsai et al. used immunoprecipitates for in vitro phosphorylation. Due to our lack of success at phosphorylating the Grb7SH2 domain using FAK, and the dearth of any other (of which we are aware) experimentally observed tyrosine kinases acting upon Grb7, we selected c-Src for our in vitro tyrosine phosphorylation studies. This decision was predicated upon the accessibility of a c-Src catalytic domain expression system, as well as the intermediate Grb7SH2 domain tyrosine phosphorylation scores for c-Src predicted by iGPS (Supplemental Data Figure S-2). 
Based upon the calculated molecular weights from our dynamic light scattering experiments, the WT-FL-Grb7 protein is approximately $128 \mathrm{kDa}$, while the Y492E-FLGrb7 protein is $87 \mathrm{kDa}$. We have interpreted these results as evidence for a dimer in the WT-FL-Grb7 case, and a more open structural monomeric form for the Y492E-FL-Grb7 protein. However, we acknowledge the possibility a monomer-dimer equilibrium for the Y492E-FL-Grb7 protein at the concentrations of the DLS studies may affect the interpretation of our measurements.

According to the Perrin factor values we obtained for the WT-FL-Grb7 and Y492E-FL-Grb7 proteins, both are approximately spherical in shape. This may be considered surprising for the Y492E-FL-Grb7 protein since a primary argument for our model is that tyrosine phosphorylation releases the full-length protein into a more open form, thus allowing accessibility to the RA-PH domains. One might expect to see this open structural form reflected in a Perrin factor suggesting an elongated shape. Yet we do not observe this. We can rationalize this result as tyrosine phosphorylation of Grb7 increasing access to the internal $\mathrm{RA}-\mathrm{PH}$ domains through an overall decrease in domain packing. This could occur without outright disengagement of full domains from the overall globular structure. Future work focused on measuring the binding characteristics of Grb7 phosphorylation mimics with known downstream signaling partners such as Filamin-a (Paudyal et al., 2013) may prove enlightening in understanding this process.

\section{Conclusions}

In this study we have characterized the oligomeric state of the full-length Grb7 protein and a tyrosine phosphorylation mimic, Y492E. In addition, we have demonstrated a preference for the phosphorylation of one tyrosine (over another) in the Grb7SH2 domain, by in vitro c-Src kinase assay. The results of these experiments indicate that mimicking tyrosine phosphorylation in the $\mathrm{SH} 2$ domain leads to a primarily 
monomeric protein. Further, the tyrosine mutated to a glutamate to provide the phosphorylation mimic, Y492E, corresponds to the tyrosine in the Grb7SH2 domain (Y80) favored for in vitro phosphorylation by c-Src. Given that dimerization is an important factor for the interaction of the Grb7 RA-PH and SH2 domains, as demonstrated by our previous studies (Siamakpour et al., 2009; Siamakpour et al., 2010) these data support our model for Grb7 activation, whereby the protein becomes monomeric upon tyrosine phosphorylation and makes available the RA-PH domains (Figure 1B). It remains to be seen whether phosphorylation of other tyrosines in the fulllength Grb7 protein are of additional importance in the regulation of Grb7 activity.

Activation of the $\mathrm{Grb} 7$ protein requires both $\mathrm{SH} 2$ domain mediated localization to the kinase and availability of the RA-PH domains for downstream protein interactions. To date, therapeutic agents have focused on targeting the $\mathrm{SH} 2$ domain by small, selective peptides, and these show some promise (Pero et al, 2007). Understanding how Grb7 is activated opens up the possibility for new approaches to combat cancers in which Grb7 is overexpressed.

\section{Acknowledgments}

We thank Dr. Lei Qian for valuable advice and discussion. We also acknowledge our funding sources, NIH grant numbers SC3 GM116728 (salary support and supplies) and P20GM103451 (supplies). The authors of this manuscript do not have any conflicts of interests, for example in interests or relationships, financial or otherwise, that could be perceived as influencing their objectivity.

\section{Authors' Contribution Statement}


A.B., R.K. and C.P. performed the research. A.B. and B.L. designed the research study. A.B. R.K. and B.L. analyzed the data. B.L. led the research effort and wrote and edited the manuscript. 


\section{References Cited}

Blom, N., Gammeltoft, S., Brunak, S.1999. Sequence and structure-based prediction of eukaryotic protein phosphorylation sites. J Mol Biol, 294(5):1351-62.

Brescia, P.J., Ivancic, M., Lyons, B.A. 2002. Assignment of backbone 1H, 13C, and $15 \mathrm{~N}$ resonances of human Grb7-SH2 domain in complex with a phosphorylated peptide ligand. J Biomol NMR, 2002. 23(1): 77-8.

Chu, P.Y., Huang, L.Y., Hsu, C.H., Liang, C.C., Guan, J.L., Hung, T.H., Shen, T.L. 2009. Tyrosine phosphorylation of growth factor receptor-bound protein-7 by focal adhesion kinase in the regulation of cell migration, proliferation, and tumorigenesis. J Biol Chem, 284(30): 20215-26.

Daly, R.J. 1996. The Grb7 family of signalling proteins. Cell Signal, 10(9):613-8.

Depetris, R. S., Wu, J., \& Hubbard, S. R. 2009. Structural and functional studies of the Ras-associating and pleckstrin-homology domains of Grb10 and Grb14. Nat Struct Mol Biol, 16(8): 833-839.

Dong, L. Q., Porter, S., Hu, D., \& Liu, F. 1998. Inhibition of hGrb10 binding to the insulin receptor by functional domain-mediated oligomerization. J Biol Chem, 273(28): 17720-17725.

Godamudunage, M., Foster, A., Warren, D., Lyons, B.A. 2017. Grb7 RA domain oligomerization. J. Molec. Recognit. Aug;30(8). doi: 10.1002/jmr.2620. Epub 2017 Mar 14.

Greenfield, N., Fasman G.D. 1969. Computed circular dichroism spectra for the evaluation of protein conformation. Biochemistry. 8 (10): 4108-4116.

Han, D. C., Shen, T. L., \& Guan, J. L. 2001. The Grb7 family proteins: structure, interactions with other signaling molecules and potential cellular functions. Oncogene, 20(44): 6315-6321.

Harding, S., Rowe, A., Horton, J.E. 1992. Analytical Ultracentrifugation in Biology and Polymer Science. 1992, Royal Society of Chemistry: Caimbridge.

Ivancic, M., Daly, R.L, Lyons, B.A. 2003. Solution structure of the human Grb7-SH2 domain/erbB2 peptide complex and structural basis for Grb7 binding to ErbB2. $J$ Biomol NMR, 27(3):205-19.

Ivancic, M., Spuches, A. M., Guth, E., Daugherty, M., Wilcox, D., Lyons, B. A. 2005. Backbone nuclear relaxation characteristics and calorimetric investigation of the human Grb7-SH2/erbB2 peptide complex. Protein Sci. 14:1556-1569.

Kim, C. W., Cho, E. H., Lee, Y. J., Kim, Y. H., Hah, Y. S., \& Kim, D. R. 2006. Diseasespecific proteins from rheumatoid arthritis patients. J Korean Med Sci, 21(3): 478484.

Krisenko, M. O., Higgins, R. L., Ghosh, S., Zhou, Q., Trybula, J. S., Wang, W. H., \& Geahlen, R. L. 2015. Syk is recruited to stress granules and promotes their clearance through autophagy. J Biol Chem, 290(46): 27803-27815.

Lacle, M. M., Moelans, C. B., Kornegoor, R., van der Pol, C., Witkamp, A. J., van der Wall, E., Rueschoff, J., Buerger, H., \& van Diest, P. J. 2015. Chromosome 17 copy number changes in male breast cancer. Cell Oncol (Dordr), 38(3): 237-245.

Lebowitz, J., Teale, M., Schuck, P.W. 1998. Analytical band centrifugation of proteins and protein complexes. Biochem Soc Trans, 26(4): 745-9.

Manser, J., Roonprapunt, C., Margolis, B. 1997. C. elegans cell migration gene mig-10 shares similarities with a family of SH2 domain proteins and acts cell nonautonomously in excretory canal development. Dev Biol, 184(1):150-64.

Ooi, J., Yajnik, V., Immanuel, D., Gordon, M., Moskow, J.J., Buchberg, A.M., Margolis, B. 1995. The cloning of Grb10 reveals a new family of SH2 domain proteins. Oncogene. 1995 Apr 20;10(8):1621-30. 
Paudyal, P., Shrestha, S., Madanayake, T., Shuster, C. B., Rohrschneider, L. R., Rowland, A., \& Lyons, B. A. 2013. Grb7 and Filamin-a associate and are colocalized to cell membrane ruffles upon EGF stimulation. J Mol Recognit, 26: (9):532-541.

Pero, S. C., Shukla, G. S., Cookson, M. M., Flemer, S., Jr., \& Krag, D. N. 2007. Combination treatment with Grb7 peptide and Doxorubicin or Trastuzumab (Herceptin) results in cooperative cell growth inhibition in breast cancer cells. $\mathrm{Br} \mathrm{J}$ Cancer, 96(10): 1520-1525.

Peterson, T.A., Benallie, R.L., Bradford, A.M., Pias S.C., Yazzie, J., Lor, S.N., Haulsee, Z.M., Park, C.K., Johnson, D.L., Rohrschneider, L.R., Spuches, A.M., Lyons, B.A. 2012. Dimerization in the Grb7 protein. J. Molec. Recognit. Aug;25(8):427-34.

Porter, C. J., Wilce, M. C., Mackay, J. P., Leedman, P., \& Wilce, J. A. 2005. Grb7-SH2 domain dimerisation is affected by a single point mutation. Eur Biophys J, 34(5): 454-460.

Porter, C.J., Matthews, J.M., Mackay, J.P., Pursglove, S.E., Schmidberger, J.W., Leedman, P.J., Pero, S.C., Krag, D.N., Wilce, M.C., Wilce, J.A. 2007. Grb7 SH2 domain structure and interactions with a cyclic peptide inhibitor of cancer cell migration and proliferation. BMC Struct Biol, 7:5873.

Pradip, D., Bouzyk, M., Dey, N., \& Leyland-Jones, B. 2013. Dissecting GRB7-mediated signals for proliferation and migration in HER2 overexpressing breast tumor cells: GTP-ase rules. Am J Cancer Res, 3(2): 173-195.

Qamra, R., \& Hubbard, S. R. 2013. Structural basis for the interaction of the adaptor protein grb14 with activated ras. PLoS One, 8(8): e72473.

Qian L.; Bradford A. M.; Cooke P. H.; Lyons B.A. 2016. Grb7_and Hax1 may colocalize partially to mitochondria in EGF-treated SKBR3 cells and their interaction can affect Caspase3 cleavage of Hax1. J Mol Recognit. Jul;29(7):318-33. doi: 10.1002/jmr.2533.

Saito, M., Kato, Y., Ito, E., Fujimoto, J., Ishikawa, K., Doi, A., Kumazawa, K., Matsui, A., Takebe, S., Ishida, T., Azuma, S., Mochizuki, H., Kawamura, Y., Yanagisawa, Y., Honma, R., Imai, J., Ohbayashi, H., Goshima, N., Semba, K., \& Watanabe, S. 2012. Expression screening of 17q12-21 amplicon reveals GRB7 as an ERBB2dependent oncogene. FEBS Lett, 586(12): 1708-1714.

Schuck, P., Perugini, M.A., Gonzales, N.R., Howlett, G.J., Schubert, D. 2002. Sizedistribution analysis of proteins by analytical ultracentrifugation: strategies and application to model systems. Biophys J, 82(2): p. 1096-111.

Seeliger, M.A., Young, M., Henderson, M.N., Pellicena, P., King, D.S., Falick, A.M., Kuriyan, J. 2005. High yield bacterial expression of active c-Abl and cSrc tyrosine kinases. Protein Sci, 14(12): 3135-9.

Siamakpour-Reihani, S., Argiros, H. J., Wilmeth, L. J., Haas, L. L., Peterson, T. A., Johnson, D. L., Shuster, C. B., \& Lyons, B. A. 2009. The cell migration protein Grb7 associates with transcriptional regulator FHL2 in a Grb7 phosphorylationdependent manner. J Mol Recognit, 22(1): 9-17.

Siamakpour-Reihani, S., Peterson, T. A., Bradford, A. M., Argiros, H. J., Haas, L. L., Lor, S. N., Haulsee, Z. M., Spuches, A. m., Johnson, D. L., Rohrschneider, L. R., Shuster, C. B., \& Lyons, B. A. 2011. Grb7 binds to Hax-1 and undergoes an intramolecular domain association that offers a model for $\mathrm{Grb} 7$ regulation. J Mol Recognit, 24(2): 314-321.

Song, C., Ye, M., Liu, Z., Cheng, H., Jiang, X., Han, G., Songyang, Z., Tan, Y., Wang, H., Ren, J., Xue, Y., Zou, H. 2012. Systematic analysis of protein 
phosphorylation networks from phosphoproteomic data. Mol Cell Proteomics, 11(10):1070-83.

Spuches, A. M., Argiros, H. J., Lee, K. H., Haas, L. L., Pero, S. C., Krag, D. N., Roller, P. P., Wilcox, D. E., \& Lyons, B. A. 2007. Calorimetric investigation of phosphorylated and non-phosphorylated peptide ligand binding to the human Grb7-SH2 domain. J Mol Recognit, 20(4): 245-252.

Stein, E. G., Ghirlando, R., \& Hubbard, S. R. 2003. Structural basis for dimerization of the Grb10 Src homology 2 domain. Implications for ligand specificity. J Biol Chem, 278(15): 13257-13264.

Tanaka, S., Pero, S. C., Taguchi, K., Shimada, M., Mori, M., Krag, D. N., \& Arii, S. 2006. Specific peptide ligand for Grb7 signal transduction protein and pancreatic cancer metastasis. J Natl Cancer Inst, 98(7): 491-498.

Tsai, N.P., Bi, J., Wei, L.N. 2007. The adaptor Grb7 links netrin-1 signaling to regulation of mRNA translation. EMBO J 26:1522-1531.

Tsai, N. P., Ho, P. C., \& Wei, L. N. 2008. Regulation of stress granule dynamics by Grb7 and FAK signalling pathway. Embo J, 27(5): 715-726.

Villalobo, A., Garcia-Palmero, I., Stateva, S. R., \& Jellali, K. 2013. Targeting the calmodulin-regulated ErbB/Grb7 signaling axis in cancer therapy. $J$ Pharm Pharm Sci, 16(2): 177-189.

Wojcik, J., Girault, J.A., Labesse, G., Chomilier, J., Mornon, J.P., Callebaut, I. 1999. Sequence analysis identifies a ras-associating (RA)-like domain in the N-termini of band 4.1/JEF domains and in the Grb7/10/14 adapter family. Biochem. Biophys. Res. Commun., 259:113-120.

Xiao, X., Hao, J., Wen, Y., Wang, W., Guo, X., \& Zhang, F. 2016. Genome-wide association studies and gene expression profiles of rheumatoid arthritis: An analysis. Bone Joint Res, 5(7): 314-319. 


\section{Figure Captions}

Figure 1. A. Domain topology and approximate residue numbering for the human Grb7 protein. B. Proposed role of tyrosine phosphorylation in Grb7 functional conformation. In the proposed model the Grb7 protein exists in an auto-inhibited form where the internal $\mathrm{RA}-\mathrm{PH}$ domains are bound with the $\mathrm{C}$-terminal $\mathrm{SH} 2$ domain, and the protein is dimerized through the $\mathrm{SH} 2$ domains (and potentially additionally the RA-PH domains).

Phosphorylation of one or more Grb7 tyrosine residues results in steric hindrance and charge repulsion that provides access to the RA-PH domains for further downstream signaling events.

Figure 2. Size Exclusion Data for Full-Length Grb7 Proteins. Overlay of the gel filtration standard curve and full-length Grb7 protein gel filtration elution profile. The lefthand $y$-axis is the molecular weight of standards while the right-hand $y$-axis is the $A_{280}$ of Grb7 protein elution. The x-axis is the ratio of the elution volume and the void volume of the column. Approximate concentrations of injected proteins were: WT-FL-Grb7: 40 $\mu \mathrm{M}$, Y492E-FL-Grb7: $30 \mu \mathrm{M}$, F511R-FL-Grb7: $60 \mu \mathrm{M}$.

Figure 3. Dynamic Light Scattering size and shape results for the WT and mutant FL Grb7 proteins. Twelve representative measurements were taken for the WT-FLGrb7 protein, while fifteen were acquired for the Y492E-FL-Grb7 protein. Panels A and C: Percent peak are vs diameter $(\mathrm{nm})$ is represented. Panels B and D: Size distribution by percent peak volume is represented.

Figure 4. In vitro Src kinase phosphorylation of WT and mutant Grb7SH2 domains. A. In Vitro Tyrosine Phosphorylation of the $\mathrm{Grb7SH} 2$ domains. In vitro tyrosine phosphorylation results for wild type $\mathrm{Grb} 7 \mathrm{SH} 2$ and the $\mathrm{SH} 2$ domain mutants $\mathrm{Y} 80 \mathrm{E}$ and 
F99R using c-Src or FAK are shown relative to no enzyme control. Tyrosine phosphorylation was detected by Western blot, using the anti-phosphotyrosine antibody, pY20. Tyrosine phosphorylation is readily observed for the wild type and F99R Grb7 SH2 domains, but not the Y80E mutant. No Grb7SH2 bands were detected using FAK, although auto-phosphorylated FAK was detected (not shown). B. c-Src Phosphorylates Grb7SH2 Domain Tyrosine 80, not Tyrosine 68. Results of in vitro tyrosine phosphorylation reactions over a comprehensive set of $\mathrm{Grb} 7 \mathrm{SH} 2$ domain mutants are shown. Importantly, the Y68F mutant, but not the Y80F mutant, is tyrosine phosphorylated. Also, the double mutant $\mathrm{Y} 68 \mathrm{~F} / \mathrm{Y} 80 \mathrm{~F}$ is not tyrosine phosphorylated, as expected. 
